REVISTA X, Curitiba, volume 14, n.4,p. 65-86, 2019

\title{
“É NORMAL NÃO SER REPRESENTADA": O APRENDIZADO DE INGLÊS POR UMA ESTUDANTE LIDA COMO NEGRA NO CENÁRIO UNIVERSITÁRIO ${ }^{1}$
}

"It is a normal situation not being represented": the English learning of a student identified as black in a university environment

Aline Nascimento BARBOSA (UFPR) ${ }^{2}$

\begin{abstract}
RESUMO: Embora a busca pelo aprendizado de uma língua estrangeira/adicional parta de diversos grupos com demarcadores sociais bem definidos, a falta de recortes torna invisíveis experiências e trajetórias de sujeitos que compõem grupos marginalizados, criando uma aparente homogeneidade que representa somente o grupo dominante. Assim, é de suma importância considerar diferentes aspectos identitários do aprendiz ao ouvir o que este teria a dizer sobre seu processo de aprendizagem, e é através de suas narrativas que entramos em contato com suas trajetórias. Este presente trabalho busca, então, elencar e analisar relatos e narrativas de uma participante negra, universitária, estudante do curso de Letras Português-Inglês em uma universidade pública de Curitiba. O trabalho está inserido na área da Linguística Aplicada, e a metodologia utilizada é qualitativa e analítica. Para tal, foram utilizadas como procedimento de geração de dados entrevistas semiestruturadas, relacionadas a observação de aulas, diários e conversas informais. Após os relatos individuais, os dados gerados são discutidos e analisados a fim de responder a pergunta de pesquisa que busca compreender como alunos universitários, lidos como negros, de baixa renda, estudantes de Letras-Inglês em Curitiba, entendem o papel da raça e da classe social em suas trajetórias como aprendizes de língua inglesa.
\end{abstract}

PALAVRAS-CHAVE: Linguística Aplicada. Identidade. Raça. Ensino e Aprendizagem. Inglês.

\begin{abstract}
Learning a second language is a milestone for any individual, which also applies for the ones who come from marginalized groups. However, not mentioning the social attributes attached to these groups creates an illusive picture of homogeneity, which translates into representation of dominant groups only. Thus, it is important to consider each and every identity trait of the learner when they share their learning process, and only by fully listening to their narratives, will we become aware of their trajectories. This work aims to present and analyze personal stories and narratives of a Black, English undergraduate student from one public university in Curitiba (PR, Brazil). This research contributes to the field of Applied Linguistics, and the methodology used is qualitative and analytic. Interviews, class observations, journals and informal conversations were used as research instruments. After the participant's account, her stories are analyzed in order to answer the research question, which aims to
\end{abstract}

\footnotetext{
${ }^{1}$ Este trabalho deriva da dissertação intitulada "Narrativas e trajetórias: o aprendizado de inglês por estudantes lidos como negros no cenário universitário", defendida em 27 de março de 2019, na Universidade Federal do Paraná, sob orientação do Prof. Dr. Eduardo Henrique Diniz de Figueiredo.

2 Mestra em Letras pela Universidade Federal do Paraná, na área de Estudos Linguísticos. (nasbar.aline@gmail.com)
} 
REVISTA X, Curitiba, volume 14, n.4,p. 65-86, 2019

learn how Black, English undergraduate students in Curitiba perceive the role that their race and social class plays in their English learning process.

KEY-WORDS: Applied Linguistics. Identity. Race. Teaching and Learning. English.

\section{INTRODUÇÃO}

Embora a busca pelo aprendizado de uma língua estrangeira/adicional parta de diversos grupos com demarcadores sociais bem definidos, a falta de recortes torna invisíveis experiências e trajetórias de sujeitos que compõem grupos marginalizados, criando uma aparente homogeneidade que representa somente o grupo dominante. Segundo Ferreira (2011), ter professores e profissionais críticos que lidem com questões raciais requer consciência sobre suas próprias trajetórias e investigar tais trajetórias nos ajuda a entender como alunos negros de baixa renda têm visto o papel de raça e classe social no ensino-aprendizagem de inglês e em sua formação. Ainda segundo Ferreira (2011), “a percepção de como se constroem as identidades em sala de aula de línguas é muito importante. Essa importância ocorre tanto com as aulas de língua materna quanto com as de língua estrangeira, pois todas trabalham com o discurso oral e escrito" (p. 126).

Ademais, como afirma Barcelos (2006, p. 148), "narrativas mostram as maneiras únicas de cada um lidar com seus dilemas e desafios. Elas são os referenciais através dos quais refletimos sobre nossas experiências e as reconstruímos baseados em novas percepções e experiências". Assim, é através das narrativas de indivíduos que entramos em contato com suas trajetórias enquanto aprendizes de uma língua estrangeira em suas posições, sempre tão singulares.

Tendo em mente a necessidade de considerar os aspectos identitários do aprendiz de língua inglesa, tenho como arcabouço teórico metodológico os conceitos de identidade em aquisição de segunda língua, considerando o "eu no mundo" de Bonny Norton (2000) para abordar as comunidades de prática de Étienne Wenger (1998) e como a própria identidade de um sujeito molda e é moldado por elas. Também partindo de Norton $(1995,2000,2011)$, temos o conceito de comunidades imaginadas. Por fim, Aparecida Ferreira $(2006,2007,2009$, 2011, 2012, 2014) enriquece o trabalho com sua vasta contribuição literária que perpassa formação de professores, aprendizado e conceito de língua e identidade racial, assim como Kubota \& Lin (2009) em seu compilado de textos que abordam identidade, língua e raça. 
REVISTA X, Curitiba, volume 14, n.4,p.65-86, 2019

A fim de compreender as vivências dos participantes, tive como pergunta de pesquisa principal: como alunos universitários, lidos como negros, de baixa renda, estudantes de Letras-Inglês em Curitiba, entendem o papel da raça e da classe social em suas trajetórias como aprendizes de língua inglesa?

Para suporte à pergunta principal, tive as seguintes perguntas adicionais:

- Em que medida a convivência universitária desestabiliza ou reifica as perspectivas de língua inglesa de alunos lidos como negros?

- Como raça e classe social têm refletido na construção de sua identidade profissional na área de Letras?

- Como raça e classe social têm se relacionado com os investimentos e comunidades imaginadas dos participantes?

\section{ARCABOUÇO TEÓRICO METODOLÓGICO}

\section{Identidade}

Em seu livro Second Language Identities, o autor David Block (2007) faz um apanhado geral sobre concepções de identidade no contexto atual, ao elencar categorias identitárias que buscam responder questionamentos que emergiam de estudos mais antigos - mais precisamente, aqueles que conceituavam identidade de modo determinista e/ou essencialista, seja por um viés biológico, seja por um viés social.

Quando se olha para grupos sociais inteiros numa incessante busca por homogeneidade baseada em atributos físicos e genéticos (cor da pele, sexo, características faciais e corpóreas, entre outros), temos o que Block (2007) intitula determinismo biológico. Por outro lado, enxergar as influências do pertencimento ao meio como atuantes, e, por vezes, determinantes no processo identitário de indivíduos configura o viés social do conceito de identidade, ao qual Block se refere como "estruturalista social". Nesse conceito, as questões biológicas deixam de ser decisivas, e o indivíduo é visto como produto do meio, moldado de acordo com seu pertencimento a diferentes categorias sociais consideradas "fixas" - por exemplo, classe social, religião, organização familiar, educação, entre outros (BLOCK, 2007, p. 12).

As visões deterministas biológica e essencialista social representam o viés estruturalista de identidade. Embora ainda vigente (KUBOTA, 1999), o estruturalismo não impera soberano: há um movimento na literatura científica sobre identidade que transita para o pós-estruturalismo - a busca por transcender os limites anteriormente 
delimitados, priorizando nuances e camadas ao invés de pré-determinações. "Os discursos pós-estruturalistas rejeitam a afirmação que teorias científicas dão acesso à verdade $^{3 ”}$ (WEEDON, 1987, p. 28), afirma Chris Weedon em 1987, em seu livro Feminist practice and poststructuralist theory. Block (2007) refere-se à autora como um dos grandes nomes do pós-estruturalismo, uma das teóricas responsáveis pelas discussões pós-estruturalistas sobre identidade "embora ela raramente use o termo" (p. 14), dando lugar ao uso da palavra "subjetividade".

Weedon (1987) evoca discussões usando como base teorias feministas que focam na identidade e na vivência da mulher numa sociedade fundada em misoginia, porém, diferentemente do que clamariam os estudos pelo viés determinista biológico, ela não associa à mulher qualquer comportamento que seja atrelado instintivamente ao grupo "mulheres", tampouco relega à mulher a posição de vítima indefesa, incapaz de transformar sua própria história. O que Weedon propõe é uma descentralização do indivíduo, do sujeito, o que, por conseguinte, retira da equação a noção de essência e permite pensar em sua subjetividade como passível de e aberta a mudanças. Pensar em identidade como subjetividade é um contraste em relação a ambas as abordagens deterministas biológicas e essencialistas sociais, e Weedon (1987) vai além ao afirmar que há um significado político na descentralização proposta: o próprio ato de abandonar a crença na essência é o que permite a transformação constante da subjetividade (p. 33).

Weedon afirma que nossas subjetividades são historicamente construídas, porém, ao mesmo tempo, "o indivíduo é sempre um lugar de formas conflitantes de subjetividade" (WEEDON, 1987, p. 33). A autora afirma que nosso "eu" é constituído ao longo da nossa vida a partir de "termos com significados", construídos antes da nossa aquisição da língua, e que essas formas de pensar e significar são usadas como base para nossa identificação em relação ao nosso lugar no mundo, nossa consciência e modo de pensar, e nosso senso de si, a própria subjetividade. Porém, Weedon reforça que não se deve esquecer que, mesmo tendo crescido como parte de um sistema específico, os significados e valores do sistema podem ser, em si, contraditórios, e o sujeito pode, então, se perceber resistindo alternativas que lhe são oferecidas compulsoriamente. Além disso, o movimento entre espaços e sistemas, o aprendizado através de outros meios de instrução que saiam do seio familiar, o envolvimento educacional e político ao

\footnotetext{
3 "poststructuralist discourses reject the claim that scientific theories can give access to truth." (WEEDON, 1987 , p. 28)

4 " (...) the individual is always the site of conflicting forms of subjectivity" (WEEDON, 1987, p. 33)
} 
longo da vida, entre outros fatores, podem ser responsáveis por nos apresentar novas alternativas para a construção de quem somos, e para a construção de novos modos de significar.

\section{Comunidades imaginadas e comunidades de prática}

Em seus estudos de 1998, Étienne Wenger adiciona outro aspecto aos conceitos de identidade: a prática. Wenger (1998) afirma que identidade e prática estão profundamente conectadas: o indivíduo negocia sua posição no mundo através da prática, e, a partir disso, negocia sua identidade. Essa posição no mundo é compartilhada por diversos outros indivíduos com características em comum, o que o autor chama de Comunidade de Prática ${ }^{5}$. Assim, para Wenger (1998), identidade é uma experiência constantemente negociada como fruto de pertencimento a uma comunidade, num processo no qual a trajetória de aprendizado do indivíduo é central. "Identidade e prática funcionam como espelhos um do outro" (WENGER, 1998, p. 149) - em outras palavras, é na prática que formamos quem somos.

Pensando no conceito inicial de Hall (1992), a comunidade de prática também trabalha com a fragmentação da identidade do sujeito, porém, em outros termos - o indivíduo é multifacetado, composto e compondo contradições transeuntes construídas socialmente ao pertencer a diversas comunidades de prática ao mesmo tempo. De acordo com Wenger, o pertencimento à comunidade de prática se dá através de três pilares: comprometimento, imaginação e alinhamento ${ }^{6}$ (WENGER, 1998, p. 173-174). É exigido do indivíduo um esforço para a manutenção do pertencimento a comunidades tão distintas, e é através do comprometimento com seu pertencimento que o sujeito negocia sua posição no mundo - referindo-se à negociação de sentido, mas também a de trajetórias e de histórias, visto que cada uma das partes coexiste com outras. Além da importância do comprometimento do membro, Wenger fala em imaginação para afirmar que muito da sensação de pertencimento a uma comunidade vem da idealização imaginada de como são os outros membros, algo puramente baseado nas experiências prévias do indivíduo. O alinhamento, por fim, transcende comprometimento e imaginação, pois exerce uma função menos interativa entre os membros: são as regras da comunidade que independem de negociação com outros membros ou de como os membros em questão são imaginados. É o pilar mais relacionado ao poder, visto que a

\footnotetext{
${ }^{5}$ Em inglês: Communities of Practice (CoP)

${ }^{6}$ Em inglês: Engagement, imagination and alignment. (WENGER, 1998, p. 173-174)
} 
sensação de pertencimento parte da necessidade ou não de se alinhar aos moldes estabelecidos por força maior - Wenger reforça que, pelo alinhamento, o membro da comunidade pode se sentir como detentor do poder, assim como pode se sentir coagido a se alinhar (WENGER, 1998, p. 181). É importante reforçar, porém, que a própria impossibilidade de negociação talvez seja uma crença compartilhada entre os membros.

Também pensando em comunidades, Norton (2000) recorre aos conceitos de comunidades imaginadas de Anderson (1983). A autora relembra que, embora o comprometimento com a comunidade de prática seja um pilar para a sensação de pertencimento, a imaginação também é essencial para o processo identitário do membro, visto que "[entender] as comunidades imaginadas provém maior entendimento sobre as identidades imaginadas" (NORTON e MCKINNEY, 2011, p. 76). Além da influência do meio, a imaginação do aprendiz, bem como a imaginação do seu pertencimento em comunidades traça não só o modo de aprendizagem do sujeito, como também seu local no mundo e sua forma de se perceber nele.

\section{LÍNGUA, IDENTIDADE E RAÇA}

\section{O que é raça?}

Raças são e foram usadas para distinguir seres humanos ao longo da história, porém, "no sentido de que categorias raciais não são determinadas biologicamente, raças não existem", afirmam Kubota e Lin (2009) nas páginas introdutórias do livro Race, Culture, and Identities in Second Language Education. Para tal afirmação, as autoras se baseiam na noção de que, mesmo que sejam tratadas como questões físicas e biológicas, os "traços" que separam os seres humanos em grupos denominados "raça" são, cientificamente falando, insuficientes para configurar o que a biologia chamaria de raça.

Em conclusão, usar "raça" como categoria descritiva/analítica é corroborar para a ideia problemática de que "raça" existe. Entretanto, as autoras também chamam atenção para o fato de que, embora construído politico e historicamente, de modo a transcender qualquer noção de homogeneidade, o termo "raça" carrega consigo uma estratégia política de mobilização e união com implicações materiais - além da violência advinda do processo colonizador de dominação, é através do construto de raça que grupos sociais podem resistir e criar entre si uma rede de apoio e solidariedade 
(KUBOTA e LIN, 2009, p. 3). As autoras afirmam que é devido a este caráter social que se fazem necessárias as contínuas pesquisas e teorizações acerca da noção de raça.

Analogicamente polêmico na geração de discussões polarizadas está o termo "etnia". Ora usado como o sinônimo politicamente correto do construto de "raça" (BLOCK, 2007), ora adotado em uma tentativa de se afastar do determinismo biológico (GOMES, 2010, p. 23), há um desalinho no que tange ao conceito de etnia, especialmente quando relacionado à raça. Joseph (2004, p. 162) explicita, brevemente, que o termo refere-se à "herança cultural compartilhada" de um grupo de indivíduos que abrange língua, espaço geográfico, tradições culturais, entre outros - , ao passo que raça busca identificar traços genéticos e físicos em determinados grupos. Similarmente ao uso de "raça", "etnia" seria outro modo de separar grupos sociais, num processo que as autoras chamam de "construção de diferenças" (JOSEPH, 2004, p. 4). Ambos os termos são usados em contextos semelhantes, de modo a representar categorias sociais definidas historicamente, e não biologicamente.

\section{Negritude e Branquitude}

Muito se discute sobre a identidade racial de pessoas negras (e asiáticas, indígenas, etc.). Entretanto, essas identidades são pareadas com a identidade "branca", de modo a tratar pessoas brancas como base do que seria a representação do ser humano. Em Unpacking White Racial Identity in English Language Teacher Education, Tonda Liggett, uma mulher que se auto intitula "branca e acadêmica" comenta como "o sentido de ser branco não é comumente discutido em uma sociedade com brancos em posição dominante" (LIGGETT, 2009, p. 27). A autora afirma que "não ver 'branco' como uma raça resulta de estar em uma posição na qual outras raças e culturas são vistas pelas lentes do padrão da branquitude" (LIGGETT, 2009, p. 35), e alerta para o perigo em tratar o aspecto racial de um sujeito como algo irrelevante, especialmente quando discussões sobre relações raciais emergem. Ao fazê-lo, há um contraste entre o que seria visto como norma (branquitude) versus a identidade racializada (todas as outras "raças"). Assim, há uma nítida divisão entre o que é válido e o que não é, entre um sistema de conhecimentos tratado como "correto", e o Outro, visto como "errado" (LIGGETT, 2009, p. 35) ou dispensável.

\footnotetext{
7 "(...) the meaning of being white is not usually discussed in a white dominant society." (LIGGETT, 2009, p. 27)

8 " (...) not seeing white as a race results from being in a position where other races and cultures are held up to the standard of whiteness" (LIGGETT, 2009, p. 35)
} 
A autora adverte que toda a construção da identidade da branquitude influencia sistematicamente os meios por onde ela se dá, inclusive os ambientes pedagógicos. A produção de sentido é baseada, também, através da ideia de conhecimento conhecimento, em si, porém, só é reconhecido e validado por questões sócio-políticas e históricas. O que é visto como conhecimento, inclusive na relação professor-aluno, aluno-aluno - e até mesmo instituição-professor-aluno - é aquele que foi definido como válido no decorrer da história da humanidade, moldado por crenças populares baseadas em movimentos históricos - como, por exemplo, a escravidão de povos africanos (p. 29). É importante entender como a branquitude também configura identidade racial, e como essa identidade se relaciona com as outras identidades raciais.

Ainda sobre branquitude, Aparecida Ferreira (2011) leva a discussão para representações no material didático usado em escolas regulares. A estudiosa defende, com base em argumentos de Silva (2003), que a chamada "ideologia do branqueamento" é trazida para e expandida por meio dos materiais didáticos, "fazendo com que a criança negra internalize essa representação estereotipada de inferioridade, culminando na auto rejeição e na rejeição do semelhante" (SILVA, 2003, p. 118). A ideologia citada é tão sutil e normatizada que pessoas brancas não reconhecem seu próprio status dominante, atribuindo às representações de branquitude valores positivos que, ao mesmo tempo, são vistos como "normais". Ao enxergar branquitude como norma absoluta, incutida enquanto ideologia silenciosa em todos os ambientes consumidos por pessoas de outras categorias raciais, a mensagem transmitida é de que membros dos grupos sociais definidos por raças não-brancas precisam se adaptar para fazer parte do mundo - e o processo de adaptação culmina em negação e auto rejeição. Ferreira ainda aposta no papel do educador para reverter a situação a fim de "não promover o sentimento de inferioridade da criança negra em relação ao material que está utilizando e nem fazer com que a criança branca crie uma aversão ou qualquer espécie de preconceito com outras etnias" (FERREIRA, 2011, p. 118).

\section{MÉTODO}

De caráter etnográfico e qualitativo, e seguindo o paradigma interpretativista, a pesquisa original tinha por objetivo analisar como alunos lidos como negros, estudantes do curso de Licenciatura Letras-Inglês, em Curitiba, entendem o papel da raça e da classe social em suas trajetórias como aprendizes de língua inglesa. A pesquisa foi de 
caráter etnográfico pelo uso de métodos tradicionalmente associados à etnografia, como a observação e a entrevista para geração de dados (BORTONI-RICARDO, 2008, p. 38).

A pesquisa aconteceu na cidade de Curitiba, visto que todos os participantes moravam na cidade. Assim, em termos de ambiente acadêmico/ educação formal, a geração de dados ocorreu em duas universidades federais na cidade de Curitiba, Paraná, aos quais chamarei de $\mathrm{A}$ e de B. Todos os participantes eram estudantes das universidades em questão. Da universidade A, foram convidados três participantes entre eles, a escolhida para a análise exposta neste artigo -, graduandos do curso Licenciatura de Letras Português-Inglês, o qual tem como objetivo formar professores para o ensino regular de línguas, além de professores das literaturas de língua portuguesa e inglesa.

Para a busca de participantes, foi definido um perfil específico de aprendiz de língua: 1) identidade racial negra, pois é preciso o recorte de raça a fim de que o aluno negro protagonize sua trajetória tendo em mente o fator racial; 2) matrícula em um curso de graduação em Letras com habilitação na língua estrangeira Inglês, para que o processo de aprendizagem de língua em ambientes formais pudesse ser observado.

Ao se trabalhar com a importância da identidade para o aprendizado, é imprescindível ouvir o que os indivíduos têm a dizer sobre si mesmos e sobre suas experiências. Para tal, foram utilizadas como procedimento de geração de dados entrevistas semiestruturadas. Juntamente às entrevistas, pedi que os participantes compartilhassem impressões pessoais em um diário. Atrelada às entrevistas e aos diários, foram feitas observações em sala de aula. Por fim, conversas informais - por vezes, em pessoa, outras vezes, através da internet (WhatsApp, Facebook ou Twitter) também intercalaram os outros instrumentos de pesquisa, em especial as observações.

Para a análise dos dados, foram levadas em consideração as construções narrativas de si de cada um dos participantes, tendo como base os estudos de identidade de Bonny Norton, os conceitos de comunidade imaginada, também da autora, as teorias sobre comunidades de prática (incluindo a noção de trajetória) de Etienne Wenger, e as discussões e problematizações acerca dos conceitos de raça a partir dos textos de Aparecida Ferreira.

A seguir, está a análise da trajetória de um dos participantes: Jane ${ }^{9}$, aluna da universidade A, graduanda do curso de licenciatura em letras português-inglês.

\footnotetext{
${ }^{9}$ Os nomes dos participantes citados são pseudônimos para proteger sua identidade, e foram escolhidos pelos próprios participantes.
} 


\section{ANÁLISE}

Jane

Eu não me sentia 'desrepresentada' porque era 'normal' eu não ser representada; é normal que os outros sejam e eu não.

Como apresentado anteriormente, Jane é uma jovem negra de 21 anos. Nascida em Passo Fundo, no Rio Grande do Sul, se mudou para Curitiba com sua família pouco depois de seu nascimento.

Tudo que conheço construí em Curitiba mesmo. (Jane, conversa pelo WhatsApp, 27/11/2018)

Ao se mudar, tinha um irmão mais novo de um mês, e, aos quatro anos, ganhou mais um irmão caçula.

Jane relata ter completado seus estudos em escolas públicas junto a seus irmãos. A estudante também reforça que seus pais sempre foram "muito conscientes" em relação à educação e que, por isso, a prole sempre teve acesso a "livros, gibis, internet e televisão a cabo", o que, segundo ela, foi essencial para sua formação "pessoal e acadêmica". Jane também reconhece que o que foi provido pela sua família não é o mais comum para a maior parte da população.

(...) eu sei que [ter acesso a livros, gibis, internet e televisão a cabo] foi essencial pra minha formação pessoal e acadêmica, inclusive no que diz respeito a aprender inglês, e entendo que muito poucos tem o privilégio de ter tudo isso na infância. O meu pai me ensinou a ler antes de eu entrar na escola, então o processo de alfabetização foi bem natural pra mim... (Jane, conversa pelo WhatsApp, 27/11/2018)

Atualmente, Jane atende a universidade A, e é graduanda do curso de licenciatura em letras português-inglês. Ao ser perguntada sobre sua motivação inicial em estudar a língua inglesa, a graduanda afirma não ter percebido o que a levou ao estudo do idioma, mas relembra os primeiros sinais de aprendizado. Ademais, sua opção por Letras foi acidental. Os excertos a seguir ilustram esse percurso da participante.

Eu acho que eu nem tive [propósito inicial em aprender inglês]... (...) Eu nunca me esqueço que a primeira palavra que eu... que eu aprendi em inglês foi together... que eu ouvia High School Musical. Aí, eu acho que eu nem tive isso, só fui aprendendo. (Jane, entrevista 1, 26/09/2017)

Na verdade, eu nem tinha vontade de fazer uma faculdade. (...) Então, aí eu olhei lá, e das coisas que tinha, eu me identificava com letras por 
causa do inglês e acabei fazendo. Então, foi mais pelo inglês que eu entrei [na faculdade de letras]. (Jane, entrevista 1, 26/09/2017)

Quando perguntada sobre seu conhecimento prévio à entrada na universidade, a estudante relembra a importância de ter acesso à internet como ferramenta para seu aprendizado. Entretanto, ao ser inserida ao meio acadêmico, Jane passou a ter consciência do próprio conhecimento, e como, para ela, segundo a mesma, foi percebida a importância da interação com outros indivíduos para o desenvolvimento de sua proficiência.

(...) não aprendi nada [de inglês] na escola, mas (...) eu não tive muita dificuldade porque... qualquer momento que eu precisasse, eu podia usar a internet... A internet, acho que ajudou bastante. (Jane, entrevista $1,26 / 09 / 2017)$

(...) aqui na faculdade, eu entrei achando que eu, nossa, sabia um monte, só que aí... Eu até sabia bastante, mas aí depois eu fiz duas disciplinas, o intermediário e o avançado, que eu percebi que, na fala, é só praticando. Tipo, só praticando pra falar mesmo, porque eu sabia um monte de coisa, sabia escrever, ler, ouvir... Mas falar falar mesmo, foi mais aqui. (Jane, entrevista 1, 26/09/2017)

Em uma das entrevistas, indaguei sobre impressões acerca do ambiente acadêmico, e em que nível havia sensação de pertencimento, tendo em mente questões de representatividade e identificação. Para esta pergunta, Jane respondeu negativamente, porém, as causas das respostas transcendiam conceitos de raça. Segundo a aluna, seu afastamento e sua não-identificação advinham de sua personalidade, que naturalmente ia de encontro aos comportamentos de seus colegas.

(...) eu não viro amiga de professor, sabe, tipo, (...) não peço nada pra ninguém, então, nesse sentido, (...) já me sinto menos porque eu acho que a galera é muito assim, sabe, todo mundo (...) é muito junto, tudo muito misturado. Mas eu não sou assim, eu venho pra cá, faço as coisas daqui e pronto, então, eu acho que às vezes eu fico meio isolada, mas como eu faço muita coisa aqui, eu acho que depende da situação. (Jane, entrevista 2, 18/10/2017)

Também indaguei mais especificamente sobre como a aluna percebia ser representada nos materiais didáticos usados para seu ensino-aprendizagem de inglês. Segundo Ferreira (2011, p. 115), ao analisar materiais didáticos e a falta de representação de pessoas negras, "o processo de construção das identidades sociais ocorre em todos os contextos e em todas instituições sociais". Jane respondeu que nunca se viu nas produções, porém alegou não se importar, visto que a falta de 
representatividade é naturalizada desde a tenra idade, através de outros meios de comunicação e entretenimento.

(...) como [não ter representatividade negra] é uma coisa que 'sempre foi assim', eu nunca prestei atenção nisso. Eu acho que nunca cheguei a me sentir excluída das coisas justamente porque sempre foi assim, então, tipo, por exemplo, desde pequenininha, sei lá, quando... (...) ah, você e seus primos e seu irmão, todo mundo assim (...) assistindo TV, tem um programinha aí, e cada um é um personagem... Eu sempre era um personagem que não tinha nada [a ver] comigo. Eu era alguém, mas eu era alguém que não tinha nada a ver comigo. Só que 'sempre foi assim', então, (...) é uma coisa que eu só tomei consciência depois. 'Nossa, por que que não tinha ninguém igual [a mim]? Ah, por causa disso, disso e disso...' Mas (...) eu não me sentia 'desrepresentada' porque era 'normal' eu não ser representada, é normal que os outros sejam e eu não. (Jane, entrevista 2, 18/10/2017)

Contemplando a fala da participante e relacionando-a aos estudos de Ferreira (2011), é possível perceber a naturalidade com que a estudante relata a falta de representatividade na infância. Embora tenha consciência, agora, dos porquês, a construção de sua identidade se deu neste contexto de não-lugar. Não se ver é "normal", de acordo com a narrativa de Jane, ao ponto de não gerar qualquer tipo de revolta ou frustração aparente. Contudo, ao relacionar essa falta de representatividade com o ambiente educacional, a estudante reflete como o fenômeno pode atingir a sala de aula se ela, ao assumir a posição de professora, não intervir e direcionar especificamente as representações usadas.

(...) [Sobre branqueamento,] eu 'tava fazendo esse material didático pro estágio e tal, e aí, eu procurei as imagenzinhas no Google (...) e daí, tipo, sei lá, "shower"... "Cartoon"... (...) 90\% das criancinhas são brancas. (Jane, entrevista 2, 18/10/2017)

Assim, ela demonstra ter consciência sobre as (faltas de) representações para a comunidade negra que, em especial, atingem as crianças (FERREIRA, 2011, 2012). Entretanto, ao perceber-se em discussões abertas sobre racismo em sala de aula, prefere isentar-se de argumentos.

$\mathrm{Eu}$ lembro que, uma vez, acho que foi no quarto ou quinto período... Quarto, talvez. Eu tinha uma matéria de literatura que não tinha a ver com inglês... Literatura portuguesa mesmo... em português. E aí, a gente 'tava falando de Monteiro Lobato, e se ele era ou não racista, essa discussão toda, e aí... 'Tava todo mundo discutindo sobre, eu não falei nada. Todo mundo discutindo se ele era ou não racista, não sei o quê, e uma colega minha que 'tava do meu lado, ela falou assim, que eu era a única pessoa negra na sala, e que eu era a única pessoa que 
não 'tava falando nada sobre. E, tipo, nem eu tinha reparado, eu 'tava só ali, ouvindo as discussões e tal. (Jane, entrevista 2, 18/10/2017)

Em seu relato, o discurso de Jane demonstra que a jovem percebe as problematizações difundidas pelo corpo intelectual dos estudos de raça, os quais analisam a falta de representatividade de sujeitos negros, o branqueamento dos corpos, e o lugar do negro na sociedade (KUBOTA e LIN, 2009; GOMES, 2010; FERREIRA, 2007, 2011, 2012). Seu discurso também sugere consciência de raça, visto que a aluna afirma que, de fato, já se percebeu como a única negra em diversos ambientes universitários. Ainda assim, Jane mantém distância do assunto, e afirma preferir não se posicionar politicamente, inclusive enquanto professora, quando exercer sua profissão futuramente. Quando perguntei o porquê, Jane recorreu a sua religião.

eu sou uma Testemunha de Jeová, aí (...) esses assuntos são muito políticos, e eu não me posiciono politicamente, então, eu não me posicionaria politicamente em frente a meus alunos, em frente a ninguém por causa disso. (...) [Esses assuntos] são sociais, mas eles envolvem a política, né, então, seria difícil pra mim esse tipo de cobrança, sabe. (Jane, entrevista 2, 18/10/2017)

No relato acima, é possível interpretar que, apesar de se perceber negra e, consequentemente, parte de um grupo marcado por marginalização, Jane tem entre os aspectos de sua identidade o alinhamento à sua religião. Embora possa parecer conflitante à primeira vista, a consciência e a criticidade que a estudante demonstra ter sobre sua trajetória de vida coexistem com sua posição política neutra devido ao comprometimento que ela detém quanto a sua espiritualidade. Jane reforça, porém, a importância de estimular o pensamento crítico de seus futuros alunos, levando as discussões para a sala de aula; a estudante ratifica que procurará não expor sua opinião.

Mas, lógico que traria os assuntos que acho que são importantes pra eles desenvolverem o pensamento crítico, aí sim. (Jane, entrevista 2, $18 / 10 / 2017$ )

Para além das entrevistas, observei aulas dos participantes durante o primeiro semestre de 2018. A aula escolhida para Jane, a que coube na agenda das duas, era de Prática de Ensino, que acontecia às terças-feiras, à tarde.

Quando observada em sala de aula, Jane não demonstra qualquer tipo de receio ou timidez. Ao chegar, senta ao lado dos colegas conhecidos, interage com os mesmos durante a aula, demonstra confiança e conhecimento acerca dos tópicos discutidos e é 
participativa. A seguir, a imagem representa a organização da sala, incluindo a posição da aluna neste ambiente.

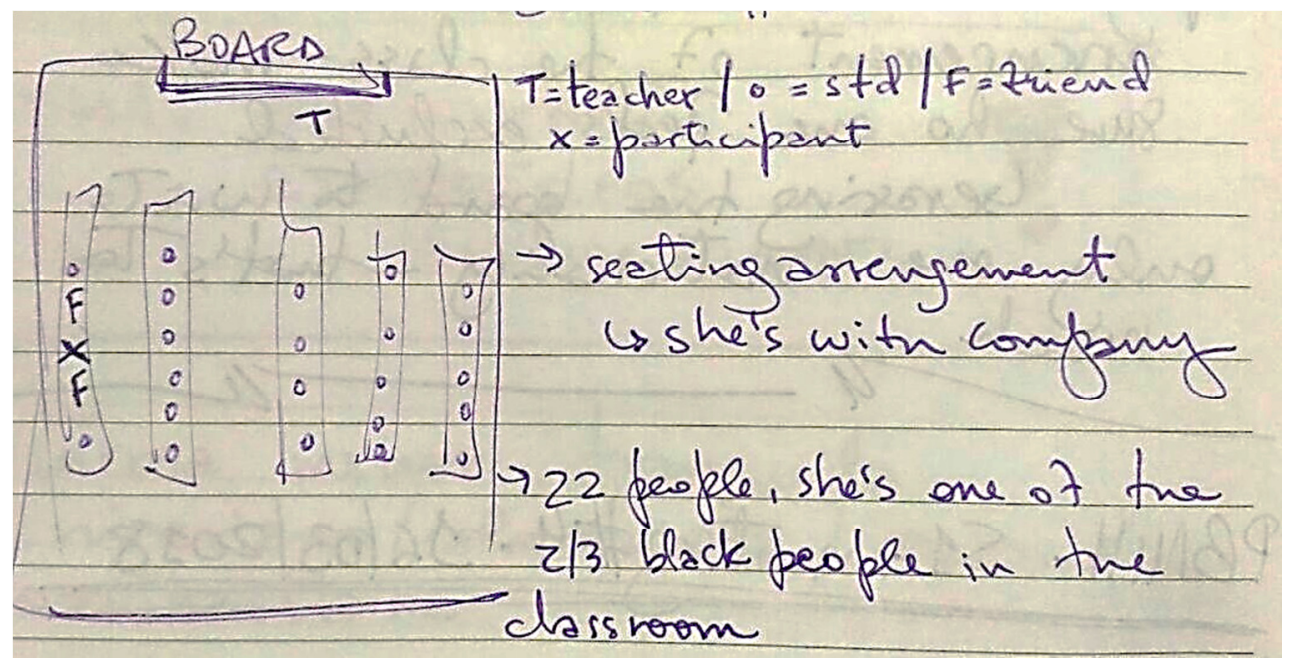

FIGURA 1 - Notas de campo, Jane, 13/03/2018

$\mathrm{Na}$ imagem, é possível ver um rascunho da organização da sala na aula observada. O "T" representa "professora", o símbolo "o" representa os alunos, a letra "X" representa Jane e "F" representa os amigos dos quais ela senta ao lado. No rascunho também é possível ver uma anotação na qual eu destacava o fato de que entre os vinte e dois alunos presentes, Jane era uma das três pessoas negras. Na disciplina observada, acontece o "micro-teaching", o que tem por objetivo explorar e aplicar conceitos de ensino a partir de apresentações de aulas em sala. É pedido que os alunos planejem uma aula curta, de 15 minutos, que tenha como foco uma das quatro habilidades, uma faixa etária e um nível previamente definidos. Os alunos, então, planejam em grupo e apresentam a aula em sala. Em uma das observações, o grupo do qual Jane fazia parte tinha uma apresentação marcada, e sua participação exprimia confiança e tranquilidade. Poderia ser esperado que uma das poucas pessoas negras do ambiente se sentisse insegura em uma apresentação em sala, porém, esse não foi caso.

Jane também escreveu, por um breve período, um diário no qual pedi que ela relatasse questões do dia a dia que envolvessem seu aprendizado de inglês e sua vivência. Em um dos relatos, a estudante revelou, em inglês, surpresas positivas sobre a percepção de seu próprio aprendizado.

Hoje, fiz uma prova de literatura inglesa. Foi interessante perceber, no meio do teste, que sou fluente na língua e capaz de responder 
REVISTA X, Curitiba, volume 14, n.4,p. 65-86, 2019

perguntas complexas. Isso já aconteceu antes, mas sempre fico surpresa. (Diário, Jane, 10/04/2018, tradução minha10)

Hoje tirei 10 em uma prova de inglês, na qual nós tínhamos que escrever um texto sobre as causas e consequências da evasão escolar. (Diário, Jane, 11/04/2018, tradução minha11)

Jane expressa orgulho de sua caminhada e de seus sucessos através da consciência de suas capacidades, ainda que em forma de surpresa em alguns momentos. Tendo como base seus relatos que denotam comprometimento com seu próprio aprendizado e reconhecimento de suas performances positivas, perguntei a Jane se a estudante sentia que precisava provar sua capacidade devido a sua posição social e raça, pergunta à qual Jane respondeu que não. Segundo a jovem, tal comportamento era indicativo de insegurança, o que ela não acredita acontecer no seu caso. Jane não parece relacionar, diretamente, atitudes acerca de seu aprendizado com aspectos de sua caminhada marcada pela participação em grupos sociais marginalizados. Contrariamente, a estudante parece associar a necessidade de auto afirmação à insegurança, sentimento que ela demonstra rejeitar, tanto verbalmente quanto por meio de comportamentos em sala.

\section{Identidade racial não implica homogeneidade}

Como discutido anteriormente, o conceito de raça é puramente social e não tem qualquer base teórica biológica (KUBOTA e LIN, 2009; GOMES, 2010; LIGGETT, 2009; FERREIRA, 2007, 2008, 2009, 2001, 2012) e, consequentemente, as pessoas lidas como brancas representam o molde neutro do que configura um "ser humano" (GOMES, 2010; LIGGETT, 2009; FERREIRA, 2011, 2012). Assim, é dada ao grupo social dominante uma folha em branco no que tange identidade - comportamentos de indivíduos membros do grupo pertencem unicamente às escolhas dos indivíduos em questão e compõem sua identidade própria, de maneira a estar descolado da imagem do grupo; os comportamentos individuais dos sujeitos não constituem um modelo para todos os membros do grupo.

Por outro lado, para os grupos racializados pelo meio, neste trabalho, especificamente os sujeitos lidos como negros, há um modelo que se espera ser seguido.

\footnotetext{
10 "Today I did an English literature test. It was interesting to notice, in the middle of the test, that I am fluent in the language, and capable of answering complex questions. This had happened before, but it always surprises me." (Diário, Jane, 10/04/2018)

11 "Today I took a grade 10 on an English test, in which we were supposed to write an essay about the causes and consequences of school evasion." (Diário, Jane, 10/04/2018)
} 
Jane representa, então, a identidade negra inesperada. Sobre as representações de negritude, podemos separá-las pelo valor atrelado a elas. Assim, temos as características ditas negativas e as características vistas como positivas. Entre as negativas, estão: 1) os estereótipos perigosos atrelados à negritude, como a violência e agressividade; 2) o sofrimento de sua trajetória. Entre as representações lidas como positivas, estaria a consciência de sua posição no mundo enquanto indivíduo negro, o que resultaria em militância vocal. Assim, tendo como base minhas próprias experiências pessoais e o relato de Jane sobre uma discussão em sala de aula que abordava racismo, é possível perceber que, em determinados momentos, seja esperado dos sujeitos negros conhecimento da causa militante, ou que atuem como porta-vozes de seu grupo social.

Jane quebra ambas as características negativas. Primeiramente, ao contar de sua própria história; mesmo reconhecendo a falta de representatividade e a dedicação extra que seus pais tiveram ao criar seus filhos, o discurso da participante não envereda para o lado da narrativa de sofrimento - é, em oposição, uma narrativa de sucesso e de luta que "deu certo", e ela percebe os efeitos positivos que sua história teve sobre sua trajetória, inclusive no que tange o aprendizado do inglês. O que ficou, para Jane, em decorrência de sua história, foi a ambição para um futuro melhor e a dedicação constante para fazer seus desejos se tornarem realidade.

Sobre as características ditas como positivas, Jane também quebra estereótipos de raça. Ao invés de demonstrar preocupações sobre a situação social do indivíduo negro, Jane apenas reconhece as questões, enquanto, ao mesmo tempo, se mantém distante do discurso de conscientização e, ainda, afirma se abster por questões religiosas. De acordo com os estudos de Wenger, cada indivíduo é composto por alinhamentos a comunidades de prática. Portanto, pode-se interpretar que o alinhamento que Jane apresenta à comunidade de "pessoas negras" é sobreposto ao alinhamento que a estudante apresenta à comunidade de prática "Testemunhas de Jeováa". O comprometimento ao grupo religioso é, também, um dos aspectos de sua identidade. Ademais, sua identificação e alinhamento também existem de acordo com as comunidades “professora de inglês", "estudante de letras”, entre outros. É importante ter em mente, em especial para as que buscam oferecer suporte político para causas sociais, que o indivíduo negro é plural. Assim como não é socialmente aceitável esperar que o grupo "pessoas negras" seja visto através de características simplórias, quando negativas, é também improdutivo esperar consciência de classe e militância de um sujeito apenas pelo grupo social do qual ele faz parte. Não há uma forma certa ou errada 
de ser negro - ser negro é uma condição social que depende da interação social, assim como qualquer outra. $\mathrm{O}$ conceito de comunidades de prática de Wenger descreve como a interação social é parte da construção da identidade do indivíduo, e Norton (1995, 2000) e Block (2007) afirmam que identidade de um indivíduo nunca está finalizada. Ferreira (2011), através dos estudos de identidade de Hall (1992), também afirma que "a identidade é algo construído e transformado ao longo do tempo por processos inconscientes de socialização, portanto não é algo inato, fixo, estável, mas em constante produção" (FERREIRA, 2011, p. 126). Ainda segundo Hall (2002, p. 13), “[...] se sentimos que temos uma identidade unificada desde o nascimento até a morte é apenas porque construímos uma cômoda estória sobre nós mesmos ou uma confortadora "narrativa do eu'” (HALL, 2002, p. 13).

Visto que a identidade é local de transformações e mudanças ao longo das trajetórias do indivíduo, é importante ter em mente que categorizar o sujeito de acordo com apenas uma das facetas de sua identidade é reduzi-lo a apenas um ponto de sua história. Assim, além de problemático, esperar posicionamentos e opiniões específicas se baseando apenas a um grupo do qual ela faz parte é buscar uma finitude e uma definição em uma história ainda em andamento. Ademais, Jane é tão negra quanto Testemunha de Jeová, quanto gaúcha crescida em Curitiba, quanto mulher, ou quanto professora em formação - e cada uma dessas comunidades está em constante transformação.

\section{CONCLUSÕES}

Como visto, as nuances nas narrativas de um indivíduo mostram a complexidade dos entendimentos sobre raça e classe social, e como tais entendimentos estão entrelaçados às trajetórias de cada um de nós. A partir dos dados gerados, posso pensar em possíveis respostas para compreender como a participante, universitária lida como negra, estudante de Letras-Inglês em Curitiba, entende o papel da raça e da classe social em suas trajetórias como aprendiz de língua inglesa. Percebi que, para a graduanda, o papel da raça e classe se faz presente de maneira nítida com reflexões acerca de sua trajetória. No entanto, os fatores que influenciam o momento e a intensidade da reflexão e da conscientização variam de acordo com diversos aspectos, entre eles estrutura familiar e experiências formais em sala de aula.

Pensando em exemplos dos fatores citados por Jane, é possível interpretar que os sinais do racismo e da falta de representatividade são percebidos, mesmo que 
inconscientemente, durante sua infância, e com as devidas atribuições sociais depois de certa maturidade. A estudante também demonstra entendimento de sua posição no mundo e relata tentar mudar o que for possível ao seu alcance - como, por exemplo, quando menciona buscar imagens de pessoas negras para serem usadas em suas atividades como professora. Interpreto, no entanto, que Jane se utiliza de sua narrativa como impulso para seu futuro - sua motivação parte, para além dos aspectos de sua personalidade, do esforço de seus pais e da constante tentativa de fazer o melhor que pode como profissional.

Seguindo a reflexão, ao pensar na convivência universitária, e como a mesma desestabiliza ou reifica as perspectivas de língua inglesa de alunos lidos como negros, Jane demonstra surpresa ao ingressar à universidade e perceber que o conhecimento prévio que tinha do inglês parecia menor do que ela acreditava ter. Sobre a questão de como raça e classe social têm refletido na construção de sua identidade profissional na área de Letras, Jane reconta momentos de seu passado nos quais não se via nos livros e nas produções culturais em geral. A estudante também relembra histórias de fragilidade socioeconômica e luta para sobreviver e para melhorar seu currículo a fim de obter mais chances para uma estabilidade financeira no futuro. Assim, as experiências de falta de representatividade a atingem, e, consequentemente, a jovem demonstra interesse em subverter branqueamento e inserir conteúdos mais inclusivos em sala de aula. O papel da raça e da classe faz com que estas questões sejam mais próximas - ao invés de buscar desconstrução e estudo para, por fim, subverter os estereótipos e os papéis tradicionalmente destinados a negros, Jane já traz, consigo, uma bagagem de conhecimento acerca da questão, advinda de suas próprias histórias de vida. Assim, o reflexo da raça e de classe transcende o processo de aprendizagem e chega às expectativas profissionais.

Por fim, ao pensar sobre como raça e classe social têm se relacionado com os investimentos e comunidades imaginadas dos participantes, Jane demonstra alinhamento com a comunidade imaginada "Testemunhas de Jeová", e sua prática em outras comunidades é um reflexo disso.

A partir dos resultados obtidos, o presente trabalho contribui para a Linguística Aplicada, no que toca questões de identidade no ensino de língua inglesa, por mostrar que indivíduos têm histórias e trajetórias diferentes, mesmo que compartilhem alinhamentos nas mesmas comunidades. As dificuldades e nuances ao se trabalhar com raça ficam visíveis quando sujeitos lidos como negros são ouvidos e as dificuldades e 
nuances atingem, também, o próprio indivíduo. É possível perceber que não há um modelo correto a ser seguido e há uma grande distância entre teoria e prática: embora lida e auto identificada como negra, quando uma turma majoritariamente branca discutia racismo, a estudante estava em silêncio. Conclui-se, então, que é pouco realista acreditar que aulas inclusivas serão produtivas apenas por termos em sala alunos. Não há garantia que aulas supostamente mais inclusivas atraiam o investimento (NORTON, 1995, 2000, 2011) de aprendizes negros. E a falta de investimento pode acontecer por diversos motivos, os quais podem variar entre gatilhos de experiências pessoais, confusão sobre sua própria identidade racial ou, até mesmo, apenas o cansaço e a falta de vontade em falar sobre algo tão presente na vida dessas pessoas. A fuga do holofote pode, por vezes, falar mais alto que um engajamento militante. É importante, entretanto, que os professores tenham, em seu processo de formação, acesso ao material intelectual de estudiosos negros. Visto que o estudante universitário negro ainda não está presente como sujeito em pesquisas acadêmicas (Ferreira, 2017), o primeiro passo para a mudança é o contato mais frequente com suas histórias. É imprescindível que professores conheçam o mínimo sobre a realidade desses indivíduos a fim de humanizalos.

\section{REFERÊNCIAS}

BARCELOS, A. Narrativas, crenças e experiências de aprender inglês. Linguagem \& Ensino, Pelotas, v. 9, p. 145-175, 2006.

BAUMAN, Z. Globalização: as conseqüências humanas. Tradução Marcus Penchel. Rio de Janeiro: Jorge Zahar, 1 ed, 1999.

BLOCK, D. Second language identities. Bloomsbury Publishing, 2007.

BONILLA-SILVA, E. Racism without racists: Color-blind racism and the persistence of racial inequality in America. Rowman \& Littlefield, 2003.

BORTONI-RICARDO, S. M. O professor pesquisador: introdução à pesquisa qualitativa. São Paulo: Parábola Editorial 2 (2008).

BOURDIEU, P. "The economics of linguistic exchanges." Information (International Social Science Council) 16.6 (1977): 645-668.

BRUNER, J. "The narrative construction of reality." Critical inquiry 18.1 (1991): 1-21.

CICONELLO, A. O desafio de eliminar o racismo no Brasil: a nova institucionalidade no combate à desigualdade racial. In: OXFAM INTERNATIONAL. (Org.). From Poverty 
to Power: how Active Citizens and Effective States can Change the World. Oxfam International: Londres, 2008.

FERNANDES, Florestan. A integração do negro na sociedade de classes. 3. ed. São Paulo: Ática, 1978, v. 1.

FERREIRA, A. What has race/ethnicity got to do with EFL teaching? Linguagem \& Ensino,v.10,n.1,p.211-233,jan./jun.2007

FERREIRA, A. Histórias de professores de línguas e experiências com racismo: uma reflexão para a formação de professores. Revista Espéculo 43 (2009).

FERREIRA, A. Raça/etnia, gênero e suas implicações na construção das identidades sociais em sala de aula de línguas. RevLet-Revista Virtual de Letras 3.02 (2011): 114129.

FERREIRA, A. Educação antirracista e práticas em sala de aula: uma questão de formação de professores. Revista de Educação Publica (UFMT), v. 1, p. 275-288, 2012.

FERREIRA, A. Teorizando Relações Étnico-Raciais no Brasil. In: Jamil Cabral Sierra; Marcos Claudio Signorelli. (Org.). Diversidade e educação: intersecções entre corpo, gênero e sexualidade, raça e etnia. 1ed. Matinhos: UFPR Litoral, 2014, v. 1, p. 83-103.

FERREIRA, A. Roda de Conversa: Política Linguística Raça e Gênero. I JILAC, Jornada Internacional de Linguistica Aplicada Crítica. Brasília: UnB, Abril/2017.

GUIMARÃES, A. "Raça e os estudos de relações raciais no Brasil." Novos Estudos CEBRAP 54 (1999): 147-156.

GOMES, N. Educação e Identidade Negra. Aletria: Revista de Estudos de Literatura, Belo Horizonte, vol. 9, p. 39-47, 2002.

GOMES, N. Educação, Identidade negra e formação de professores/as: um olhar sobre o corpo negro e o cabelo crespo. Educação e Pesquisa, v.29, n.1, p.167-182, 2003.

GOMES, N. Alguns termos e conceitos presentes no debate sobre relações raciais no Brasil: Uma breve discussão. In: MUNANGA, Kabengele. Educação AntiRacista: Caminhos abertos para Lei Federal 10.639/03. Secretaria de Educação Continuada, Alfabetização e Diversidade. Brasília: Ministério da Educação, Secretaria de Educação Continuada, Alfabetização e Diversidade, 2005. 236 p.

GOMES, N. "Educação, relações étnico-raciais e a Lei 10.639/03: breves reflexões." BRANDÃO, Ana Paula. Modos de fazer: caderno de atividades, saberes e fazeres. Rio de Janeiro: Fundação Roberto Marinho (2010).

GOMES, Nilma Lino; MIRANDA, S. A. . Genero, raça e educação: indagações adivindas de um olhar sobre uma academia de modelos. POIÉSIS - Revista do Programa de Pós-Graduação em Educação (Unisul), Florianópolis. v. 8, p. 81-103, 2014.

HALL, S. A identidade cultural na pós-modernidade. 10 ed, DP\&A Editora. 1992 
HEIGHAM, J., CROCKER, R. Qualitative research in applied linguistics: A practical introduction. Springer, 2009.

JOSEPH, J. Language and identity. London: Palgrave. 2004

KINCHELOE, J, STEINBERG, S. Changing multiculturalism. Open University, 1997.

KUBOTA, R., LIN, A. Race, culture, and identities in second language education: Exploring critically engaged practice. Routledge, 2009.

KUBOTA, R. "Japanese culture constructed by discourses: Implications for applied linguistics research and ELT." TESOL quarterly 33.1 (1999): 9-35.

LIGGETT, T. Unpacking white racial identity in English language teacher education. Race, culture, and identities in second language education: Exploring critically engaged practice (2009): 27-43.

LUKE, A. Race and language as capital in school: A sociological template for language education reform. In: KUBOTA, Ryuko; LIN, Angel. Race, culture and identities in second language education: Exploring critically engaged practice New York, NY: Routledge, 2009, p. 286-308.

NORTON, B. \& MCKINNEY, C. An identity approach to second language acquisition. In D. Atkinson (Ed). Alternative approaches to Second Language Acquisition (pp. 7394). New York: Routledge. 2011

NORTON, B. Identity and language learning: Gender, ethnicity and educational change. Harlow: Pearson Education. 2000

NORTON PEIRCE, B. Social identity, investment, and language learning. TESOL Quarterly, 29(1), 9-31. 1995

QUEIROZ, M. Relatos orais: do 'indizível' ao 'dizível'. In: VON SIMSON, Olga Moraes. Experimentos com histórias de vida: Itália-Brasil. São Paulo: Vértice; Revistas dos Tribunais, 1988. p. 14-43.

WEEDON, C. Weedon. Feminist practice and poststructuralist theory. Oxford: Blackwell, 1987.

WENGER, E. Communities of practice: Learning as a social system. Systems thinker, v. 9, n. 5, p. 2-3, 1998. 
REVISTA X, Curitiba, volume 14, n.4,p. 65-86, 2019

\section{APÊNDICE 1 - ENTREVISTA 1}

1. Qual foi seu propósito inicial em aprender inglês? / Por que inglês?

2. Quando você começou a estudar inglês? / Quais meios foram utilizados para aprender inglês?

3. Por que letras?

4. O que mais dificulta/dificultou seu aprendizado?

5. Descreva brevemente sua trajetória de aprendizado de inglês.

6. Em sua opinião, o que significa "ser proficiente em inglês"?

7. Você se considera proficiente em inglês? Justifique.

\section{APÊNDICE 2 - ENTREVISTA 2}

1. Você se sente parte de suas turmas? Explique.

2. Você enxerga pessoas que se parecem com você nos materiais didáticos [nas suas aulas da faculdade]? Explique.

3. Você já ouviu falar no termo branqueamento? [O que você sabe disso?]

4. Você acha que seus professores abordam o tema raça em sala de aula?

5. Você considera raça um tema tabu? Acha que seus professores/seus colegas consideram raça um tema tabu?

6. Você considera gênero um tema tabu? Acha que seus professores/seus colegas consideram gênero um tema tabu?

7. Quando pensa no seu futuro enquanto professor, você se imagina falando de raça e gênero em sala de aula? 